\title{
Article \\ Humoral Response to Microbial Biomarkers in Rheumatoid Arthritis Patients
}

\author{
Seyedesomaye Jasemi ${ }^{1}$, Gian Luca Erre ${ }^{2,3}$, Maria Luisa Cadoni ${ }^{2,3}$, Marco Bo ${ }^{1}$ and Leonardo A. Sechi ${ }^{1,4, *(D)}$ \\ 1 Department of Biomedical Sciences, University of Sassari, Viale San Pietro 43b, 07100 Sassari, Italy; \\ s.jasemi@studenti.uniss.it (S.J.); m.bo4@studenti.uniss.it (M.B.) \\ 2 Department of Medical, Surgical and Experimental Sciences, University of Sassari, 07100 Sassari, Italy; \\ glerre@uniss.it (G.L.E.); sardinia@hotmail.com (M.L.C.) \\ 3 Dipartimento di Specialità Mediche, Azienda Ospedaliero Universitaria di Sassari, 07100 Sassari, Italy \\ 4 Struttura Complessa di Microbiologia e Virologia, Azienda Ospedaliera Universitaria di Sassari, \\ 07100 Sassari, Italy \\ * Correspondence: sechila@uniss.it; Tel.: +39-079228462
}

Citation: Jasemi, S.; Erre, G.L.;

Cadoni, M.L.; Bo, M.; Sechi, L.A.

Humoral Response to Microbial Biomarkers in Rheumatoid Arthritis Patients. J. Clin. Med. 2021, 10, 5153. https://doi.org/10.3390/jcm10215153

Academic Editors: Muh-Shi Lin and Andrew Chih Wei Huang

Received: 30 September 2021

Accepted: 31 October 2021

Published: 2 November 2021

Publisher's Note: MDPI stays neutral with regard to jurisdictional claims in published maps and institutional affiliations.

Copyright: (c) 2021 by the authors. Licensee MDPI, Basel, Switzerland. This article is an open access article distributed under the terms and conditions of the Creative Commons Attribution (CC BY) license (https:/ / creativecommons.org/licenses/by/ $4.0 /)$.

\begin{abstract}
Background/Objective: Chronic humoral immune response against multiple microbial antigens may play a crucial role in the etiopathogenesis of rheumatoid arthritis (RA). We aimed to assess the prevalence and magnitude of antibody response against various bacterial and viral immunogen peptides in the sera of RA patients compared with the general population. Methods: Polyclonal IgG antibodies (Abs) specific for peptides derived from Porphyromonas gingivalis (RgpA, Kpg), Aggregatibacter actinomycetemcomitans (LtxA1, LtxA2), Mycobacterium avium subsp. paratuberculosis (MAP4027), Epstein-Barr virus (EBNA1, EBVBOLF), and human endogenous retrovirus (HERV-W env-su) were detected by ELISA in serum samples from 148 consecutive RA patients and 148 sex and age-matched healthy controls (HCs). In addition, the presence of a relationship between the positivity and the titer of antibodies and RA descriptors was explored by bivariate correlation analysis. Results: RA patients exhibit a higher prevalence of humoral immune response against all tested peptides compared to HCs with a statically significant difference for MAP4027 (30.4\% vs. $10.1 \%)$, BOLF (25.7\% vs. $8.1 \%)$, RgpA (24.3\% vs. $9.4 \%)$, HERV W-env (20.3\% vs. 9.4\%), and EBNA1 (18.9\% vs. 9.4\%) peptides. Fifty-three (35.8\%) out of 148 RA serum and 93 (62.8\%) out of $148 \mathrm{HCs}$ were negative for all pathogen-derived peptides. There was a significant correlation between OD values obtained by ELISA test against all peptides $(p<0.0001)$. We also found an increased titer and prevalence of Abs against LtxA1 and LtxA2 in seropositive vs. seronegative RF ( $p=0.019$, $p=0.018$ ). Conclusion: This study demonstrates a significantly increased humoral response against multiple pathogens in patients with RA and implies that they could be an important factor in the pathogenesis of the disease. Therefore, the role of each individual pathogen in RA needs to be further investigated.
\end{abstract}

Keywords: rheumatoid arthritis; immune response; P. gingivalis; A. actinomycetemcomitans; M. avium subspecies paratuberculosis; Epstein-Barr virus; human endogenous retroviruses

\section{Introduction}

Rheumatoid arthritis (RA) is a chronic systemic autoimmune disorder affecting $0.5-1 \%$ of people worldwide [1]. The main clinical manifestation of the disease is the chronic inflammatory process in the joints, which results in bone damage, loss of function, and reduced independence in performing daily activities [2].

The etiology of RA is not well understood. However, several triggers, such as smoking, infections, and microbiota, have been identified as risk factors for initiating and exacerbating the disease in genetically susceptible individuals [3]. Autoantibodies against different self-antigens such as rheumatoid factor (RF) and anti-citrullinated protein antibody (ACPA) are considered immunological markers of RA and can be found years before 
the onset of overt symptoms [4]. Recent studies have suggested that mucosal surfaces, specifically the periodontium, the gut, and the lungs, might be privileged sites of autoimmunity initiation in RA [5] ignited by a humoral and cytotoxic immune response against mucosal-associated pathogens [6]. Accordingly, there is convincing evidence that immunity against mucosal microbial pathogens such as Porphyromonas gingivalis (P. gingivalis) and Aggregatibacter actinomycetemcomitans (A. actinomycetecomitans) may be linked to RA development [7-10]. RA-related autoantibodies against these pathogens are stimulated in different ways. PPAD—an enzyme with citrullination activity against P.g —and LtxA —an enzyme with hyper citrullination activity via neutrophil osmotic lysis to A.a-are known as essential factors to sustain RA development [11-13].

Higher prevalence with respect to the general population of the humoral immune response against Mycobacterium avium subsp. paratuberculosis (MAP), Epstein-Barr virus (EBV), and human endogenous retrovirus (HERVs, ancient viruses integrated into the human genome) has also been demonstrated in patients with several immune-mediated states, including RA [14-17].

Among mechanisms potentially involved in microbial-driven RA pathogenesis, molecular mimicry, epitope spreading, and bystander activation are the most commonly reported [7].

A comprehensive demonstration of the role of the immune response against multiple pathogens in RA pathogenesis is still lacking. Therefore, this study aimed to evaluate the prevalence and magnitude of the immune response against different highly immunogen microbial peptides derived from P. gingivalis (RgpA, Kpg), A. actinomycetecomitans (LtxA-1, LtxA-2) MAP (MAP_4027 $18-32$ ), EBV (EBNA1 $400-413$, BOLF1 $1_{305-320}$ ), and HERV-W env-su 93-108 in RA patients compared with the general population.

\section{Materials and Methods}

\subsection{Subjects}

Consecutive unselected RA patients attending the outpatient Rheumatology Unit at the Department of Clinical and Experimental Medicine of the University of Sassari (Italy) during the period between 2019 and 2020 and fulfilling the 2010 American College of Rheumatology classification criteria $[18,19]$ were enrolled in the study. To evaluate the presence of correlations between humoral immune response and RA-specific features, the following disease-specific scores, disease descriptors, and treatment data were collected: current steroid treatment; cumulative dosage of steroids (last 12 months); current treatment with biological or targeted-synthetic disease-modifying anti-rheumatic drugs ( $b$ /tsDMARDs); current use of methotrexate; cumulative; C-reactive protein (CRP) concentrations, mg/dL; erythrocyte sedimentation rate (ESR), $\mathrm{mm} / \mathrm{h}$; Disease Activity Score-28 (DAS-28); Clinical Disease Activity Index (CDAI). In addition, as a control group, we enrolled age- and sex-matched healthy blood donors attending the local blood transfusion service.

The Ethics Committee of the University of Cagliari approved this study (PG 2018/5643). Informed consent was obtained from all individual participants.

\subsection{Peptide Synthesis}

Peptides derived from $P g$ (RgpA: ADPVVTTQNIIVT and Kgp: VTDLYYSAVDGD) and $A a$ (LtxA-1: AWENKYGKNTFENGYDA and LtxA-2: TALIKAAQKLGIEVYHE) were designed using the Immune Epitope Database and Analysis Resource (IEBD) and synthesized at $>95 \%$ purity (LifeTein, South Plainfield, NJ, USA). Peptides derived from EBV (EBNA1 ${ }_{400-413}$ : PGRRPFFHPVGEAD), BOLF1 $1_{305-320}$ : AAVPVLAFDAARLRLLE), MAP (MAP_402718-32: AVVPVLAYAAARLL), and HERV-W (HERV-W env-su 93-108: NPSCPGGLGVTVCWTY) were selected from previous studies [20-22]. All peptides were dissolved in dimethyl sulfoxide (DMSO) and stored at $-80^{\circ} \mathrm{C}$ in single-use aliquots $(10 \mathrm{mM})$. 


\subsection{Enzyme-Linked Immunosorbent Assay (ELISA)}

Sera were separated according to the standard method [23]. Briefly, we allowed blood to clot for 30-60 $\mathrm{min}$ at room temperature. Then, we centrifugated it for $10 \mathrm{~min}$ at approximately $1000 \mathrm{~g}$, and aliquoted serum were preserved at -80-degree freezer. Indirect ELISA was carried out to detect specific Abs against the select antigens included in the study, as reported previously [24]. Briefly, $10 \mu \mathrm{g} / \mathrm{mL}$ of each peptide with a solution $0.05 \mathrm{M}$ of carbonate-bicarbonate, pH 9.5 (Sigma-Aldrich, St. Louis, MO, USA) were coated in 96-well plates and incubated overnight at $4 \circ \mathrm{C}$. Plates were incubated for one hour at room temperature (RT) in a blocking solution with 5\% non-fat dried milk (Sigma-Aldrich, St. Louis, MO, USA) and phosphate-buffered saline (PBS) (Sigma-Aldrich, St. Louis, MI, USA) and washed twice with $0.05 \%$ Tween-20-PBS 1 X (PBS-T) (Sigma-Aldrich, St. Louis, MI, USA). Then, one microliter of serum samples was added to plates and incubated for two hours. Then, each plate was washed five times in PBS-T and incubated for one hour at RT with $100 \mu \mathrm{L}$ of PBS and anti-human IgG polyclonal antibody (1:1000, Sigma-Aldrich, St. Louis, MI, USA). After another washing step in PBS-T, plates were incubated in a dark environment for eight to ten minutes in milli-Q water and p-nytrophenyl phosphate (Sigma-Aldrich, St. Louis, MI, USA), and the optical density was read at a wavelength of $405 \mathrm{~nm}$ using a microplate reader (Molecular Devices, Sunnyvale, CA, USA). All samples were repeated in triplicate, and positive controls were used for each peptide. The obtained absorbance values (at $405 \mathrm{~nm}$ ) were normalized to a highly positive control serum with absorbance reactivity set at 1.0 arbitrary units $(\mathrm{AU} / \mathrm{mL})$. Results are expressed as means of triplicate $405 \mathrm{~nm}$ OD values.

Intra-assay variation was calculated based on the mean of the $\mathrm{CV}$ percentages $(\% \mathrm{CVs})$ obtained from OD measurements repeated three times for each serum in three-well plates. Inter-assay variation was calculated based on the mean of $\% \mathrm{CVs}$ obtained from experiments repeated three times for each serum in three separate plates during three different days. Inter-assay variation was done for 40 serum samples with high, low, and moderate ODs.

\subsection{Statistical Analysis}

The results were expressed as a mean of three separate experiments, and the analysis was performed using GraphPad Prism version 8.0 software (San Diego, CA, USA).

A T-test and Fisher's exact test were performed to analyze the matching age and sex in RA patients with HC group. The Mann-Whitney test was performed for non-parametric comparisons. A value of $p<0.05$ was considered significant. The cut-off for positivity was established in the interval $0.35-0.52(\mathrm{AU}) / \mathrm{mL}$ based on the receiver operating characteristic (ROC) curve with $\geq 90 \%$ specificity and $95 \%$ confidence interval. In addition, Fisher's exact test was employed to compare the percentages of positive subjects in the two groups. The correlation between OD values obtained by the ELISA test from different peptides, and the RA features, RA activity (DAS-28), systemic inflammation (ESR, CRP), and type of immunosuppressive treatment was explored by bivariate correlation and regression analysis with Stata.

\section{Results}

This retrospective case-control study examined a set of serum samples derived from 148 RA patients (123 females, 25 males; median \pm SD: $65.2 \pm 9$ ) and 148 healthy controls (120 females, 28 males; median \pm SD: $63.5 \pm 7$ ). The demographic and clinical features of all subjects involved in the present study are summarized in Table 1. 
Table 1. Demographic and clinical characteristics of patients and healthy controls tested.

\begin{tabular}{cccc}
\hline & $\begin{array}{c}\text { Rheumatoid Arthritis } \\
\boldsymbol{n}=\mathbf{1 4 8}\end{array}$ & $\begin{array}{c}\text { Healthy Controls } \\
\boldsymbol{n}=\mathbf{1 4 8}\end{array}$ & $\boldsymbol{p}$ Value \\
\hline Age, years & 65.2 & 63.5 & $p>0.077$ \\
Female, $n$ (\%) & $123(83.1)$ & $120(81)$ & $p>0.76$ \\
Disease duration, months & $108(8.2)$ & $/$ & \\
ACPA, $(\%)$ & 74.2 & $/$ & \\
RF, $(\%)$ & 81.0 & $/$ & \\
DAS28 & $3.9(0.1)$ & $/$ & \\
CDAI & $10.9(0.7)$ & $/$ & \\
CRP, mg/L & $3.7(2.4)$ & $/$ & \\
ESR, mm/h & $32.3(1.8)$ & $/$ & \\
Steroid use, $n(\%)$ & 37.1 & $/$ & \\
DMARDs use, $(\%)$ & 70.2 & $/$ & \\
Methotrexate use, $(\%)$ & 55.7 & $/$ & \\
TNFi use, $(\%)$ & 23.4 & 4.7 & \\
Abatacept use, $(\%)$ & 5.4 & $\%)$ &
\end{tabular}

Values are mean and proportions. DAS28, Disease Activity Score-28; CDAI, clinical disease activity index; ACPA anti-citrullinated peptide antibodies; RF, rheumatoid factor; CRP, C-reactive protein concentrations, $\mathrm{mg} / \mathrm{dL}$ ESR, erythrocyte sedimentation rate, $\mathrm{mm} / \mathrm{h}$; DMARDs, synthetic disease-modifying anti-rheumatic drugs; TNFi, tumor necrosis factor inhibitors.

No significant difference was observed between the age and sex of HC compared to RA patients' groups ( $p>0.077$ and $p>0.76)$.

The variation was from $7.2 \%$ to $9.6 \%$ for intra-assay and from $10.1 \%$ to $13.7 \%$ for inter- assay.

Among the tested immunogen peptides, the highest titer of antibodies was demonstrated against the MAP4027 peptide, corresponding to a seroreactivity of $30.4 \%(n=45)$ among RA patients and $10.1 \%(n=15)$ in HCs (AUC $=0.736, p<0.0001)$ (Figure 1A, Figure 2$)$.

We also demonstrated a strong $\mathrm{Ab}$ response against both $P$. gingivalis-derived peptides in RA sera compared with HCs that reached statistical significance for the RgpA peptide $(p<0.0001)$ (Figure 1B,C). Therefore, $36(24.3 \%)$ out of 148 RA sera and $14(9.4 \%)$ out of $148 \mathrm{HCs}$ sera were anti-RgpA positive (AUC $=0.705, p=0.001$ ) (Figure 1B, Figure 2). On the contrary, the humoral immune response against $A$. actinomycetecomitans-derived peptides was not significantly different between groups (Figure 1D,E).

Similarly, as expected, the titer and prevalence of Abs against EBV (EBNA1, BOLF1) was significantly higher in RA sera than in the counterpart $(p<0.0001)$ (Figure $1 F, G)$. This corresponds to $38(25.7 \%)$ and $28(18.9 \%)$ of RA sera being positive for BOLF and EBNA1 compared with $12(8.1 \%)$ and $14(9.4 \%)$ of control sera, respectively (AUC $=0.647$, and AUC $=0.736$, respectively; $p<0.0001$ and $p=0.029$, respectively) (Figure 1F,G; Figure 2).

In addition, Abs titers against peptides derived from HERV-W (HERV-W env-su) were significantly higher in RA than in HCs $(p<0.0001)$ (Figure $1 \mathrm{H})$. This figure corresponds to $20.3 \%(n=30)$ of RA sera seropositivity against anti-HERV-W env-su compared with $9.4 \%$ $(n=14)$ of its counterpart (AUC $=0.736, p<0.0001 ; p=0.013$ ) (Figure 1H, Figure 2).

In total, $53(35.8 \%)$ out of 148 RA sera and $93(62.8 \%)$ out of 148 HCs were negative for all tested peptides $(p<0.0001)$.

There was no significant difference between OD values in patients $<1$ year disease duration compared with patients $>1$ year disease duration $(p>0.05)$.

Of note, we found an increased titer and prevalence of antibodies against LtxA1 and LtxA2 in seropositive vs. seronegative RF among RA patients (Figure 3). The correlation analysis between remaining RA predictors and Abs was not significant (Table S1). 

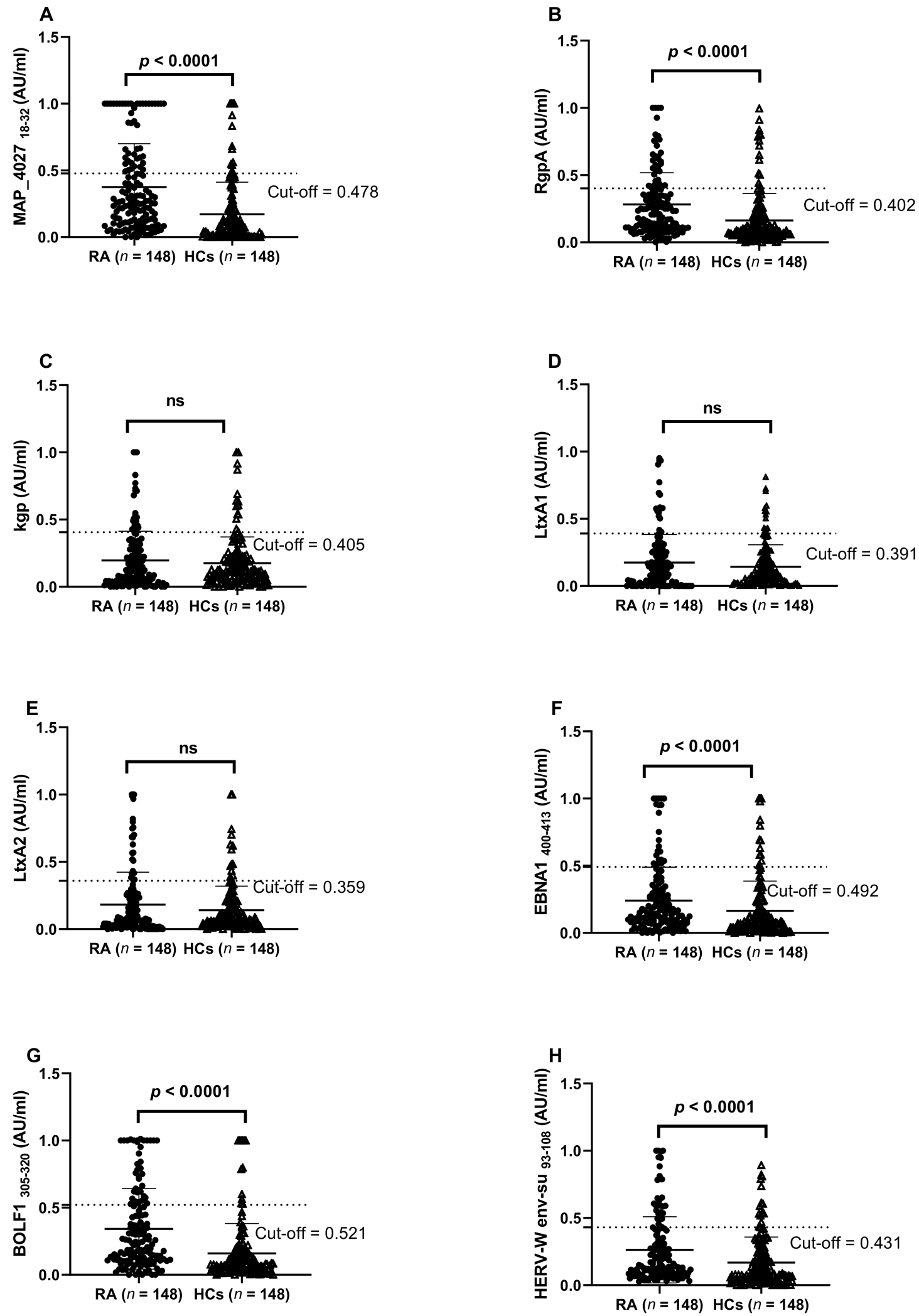

Figure 1. ELISA-based analysis of Abs reactivity against pathogenic microorganism-derived peptides in RA patients and HCs. Sera samples were tested against plate-coated (A) MAP4027, (B) RgpA, (C) Kpg, (D) LtxA1, (E) LtxA2, (F) EBNA1, (G) EBVBOLF, and (H) HERV-W env peptides. Dashed lines represent thresholds used to assess the samples' positivity (cut-off value based on the ROC curve with $\geq 90 \%$ specificity and $95 \%$ confidence interval). 


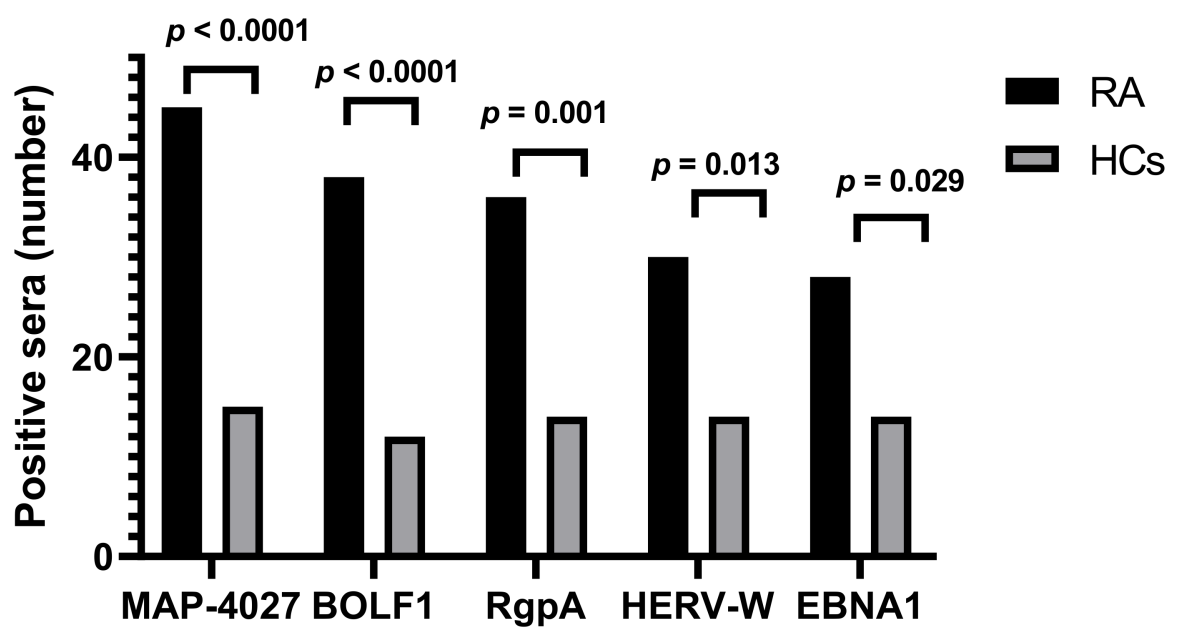

Figure 2. Number of sera positive to MAP4027, BOLF1, RgpA, HERV-W, and EBNA1 peptides in RA and HCs (Fisher's exact test: $p<0.05)$.
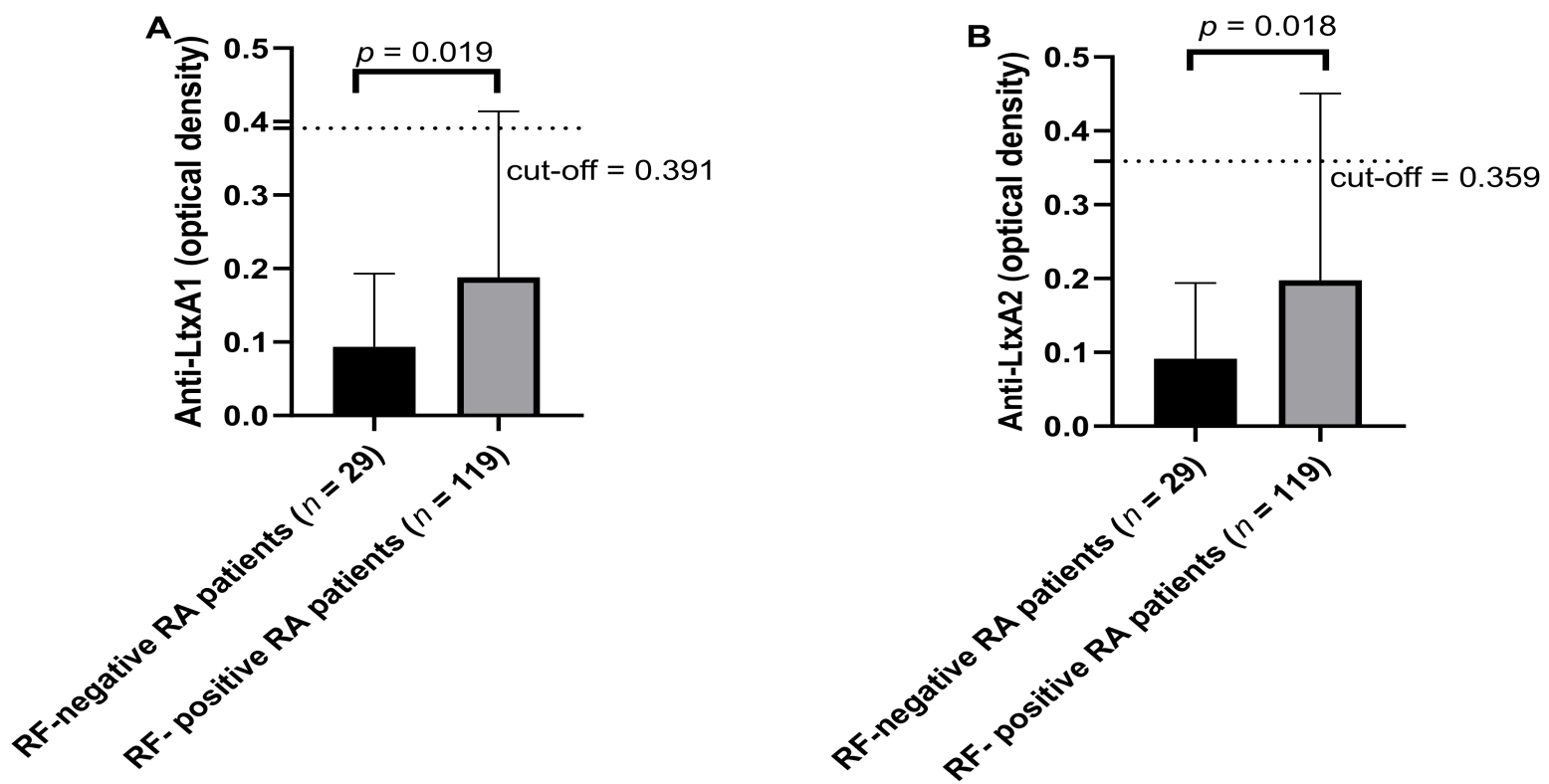

Figure 3. Abs response against LtxA1 (A) and LtxA2 (B) in RF-positive RA patients vs. RF-negative RA patients. The black bars represent the average $\pm S$, dashed lines represent thresholds used to assess the samples' positivity.

Correlation analyses were performed according to OD values obtained by ELISA test for different peptides (Figure 4).

There was a significant correlation between all Abs $(p<0.05)$. Higher correlation was observed between anti-LtxA2 and anti-Kpg $(r=0.652, p<0.0001)$ followed anti-HERV-W andanti-LtxA2 $(r=648, p<0.0001)$, anti-LtxA1 and anti-LtxA2 $(r=641, p<0.0001)$, antiMAP4027 and anti-HERV-W $(r=0.637, p<0.0001)$, anti-Kpg and anti-HERV-W $(r=0.635$, $p<0.0001)$, anti-HERV-W and anti-RgpA $(r=0.632, p<0.0001)$, anti-LtxA1 and anti-Kpg $(r=0.628, p<0.0001)$, and anti-HERV and anti-LtxA1 $(r=0.627, p<0.0001)$. The heatmap (Figure 4 ) shows the $r$ values between pairs of epitopes. 


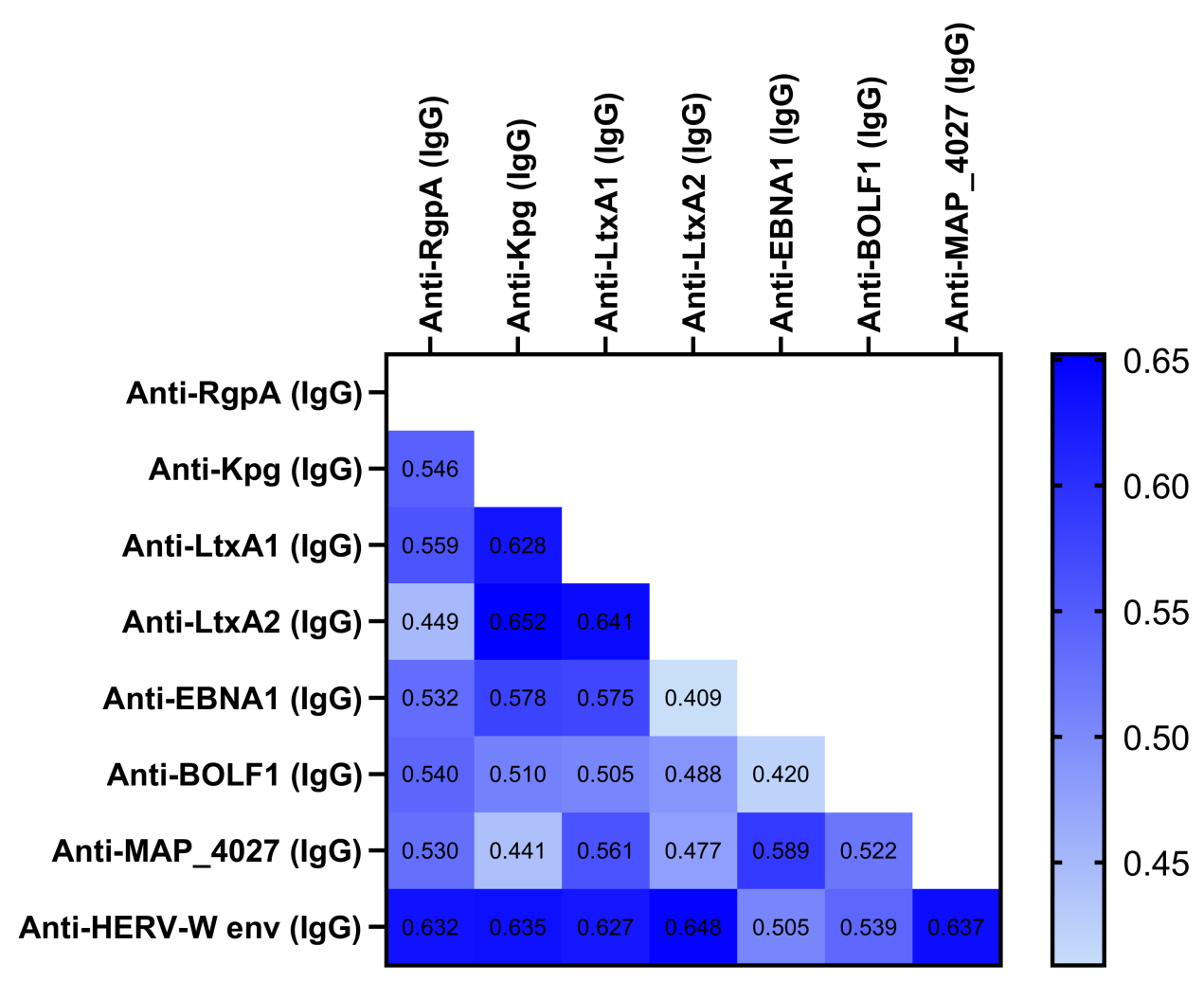

Figure 4. Heatmap displaying the $r$ values obtained from Spearman correlation analysis performed among derived peptides.

\section{Discussion}

Several environmental factors, including infections, have been associated with an increased risk of RA $[7,25,26]$.

We tested the humoral response against selected peptides derived from pathogens previously associated with RA, including $P$. gingivalis, A actinomycetemcomitans, MAP, EBV, and HERV-W in RA patients in comparison to HCs. We found that the highest prevalence of humoral response was against MAP, suggesting a contributing role for this microorganism in RA development $[8,10]$. After colonization of MAP in the host, it can evade the immune system through different mechanisms such as molecular mimicry, which is a condition that may lead to the host immune system targeting self-epitopes [7].

This bacterium is the causative agent of paratuberculosis, which is a disease predominately found in ruminants that may spread to human hosts by water and foodborne transmission routes [27]. This pathogen is associated with Crohn's disease and other autoimmune diseases in humans [27]. The potential role of MAP in RA has been already highlighted in a previous study in which RA sera showed a remarkably frequency of reactivity against PtpA $(p<0.001)$ and PknG $(p=0.0054)$ peptides in comparison to HCs [10]. A significant linear correlation between the number of swollen joints and the concentrations of antibodies against PtpA was also found $(p=0.018)$ [10]. Accordingly, we previously demonstrated significant cross-reactivity between MAP (MAP4027) and interferon regulatory factor 5 peptide (IRF5 ${ }_{424-434}$ ) [20] in RA.

In this study, the $\mathrm{Ab}$ response against peptides derived from lysogenic phase (BOLF1) and latent phase (EBNA1) proteins of EBV was significantly higher in RA patients compared with the control group. This result support previous evidence regarding the role of EBV in RA $[28,29]$. Of note, EBV is potentially involved in the activation and stimulation of HERV-K expression [30-32]. For the first time, we found a strong reactivity in RA against the selected surface epitope of HERV-W (HERV-W env-su 93-108). These results are in line with other studies reporting increased humoral responses to EBV and HERV-K peptides in 
Sardinian patients with different autoimmune diseases, including RA [28,33]. Interestingly, our results have shown high correlation between the HERV-W env peptide and LTX2, MAP4027, Kpg, and RgpA, which probably supports the hypothesis that these pathogens might act synergically to induce autoimmunity through a common target.

Furthermore, we found that RA compared with HCs show a higher prevalence of humoral response against peptides derived by periodontal pathogens, which was statistically meaningful for the anti-RgpA IgG peptide. This is in line with findings from epidemiological studies suggesting a potential pathogenic link between periodontitis and RA $[11,34,35]$. P. gingivalis and A. actinomycetecomitans are the most common reported pathogens in periodontitis, and they can contribute to RA autoantibody production through various mechanisms: directly by post-translation modification of human protein (by the PPAD enzyme of $P$. gingivalis) or indirectly by neutrophil osmotic lysis (leukotoxin of Aa) $[9,11-13]$. In this study, we found a positive significant correlation between anti-LtxA2 and anti-Kpg, and also, anti-LtxA1 and anti-LtxA2 with RF, suggesting that $P$. gingivalis and $A$. actinomycetecomitans may cooperate in inducing immunity against periodontal and synovial self-antigens. Although data from in vitro and in vivo studies on the interaction between these two pathogens are scarce, co-infection seems to be associated with poor RA prognosis [36]. One potential limitation of the current study is the absence of RA patients in the preclinical period for the evaluation of antibodies against our peptides. Moreover, a lack of anti-CCP titer and its quantitative evaluation among RA patients is another limitation of this investigation.

In conclusion, this study demonstrated a link between different pathogens and RA. The exposure to these pathogens, either in the preclinical period (before the disease onset) or during the clinical phase, is likely to have a pivotal role in the emergence and maintenance of RA. Further investigations are needed to confirm these results in larger groups of RA patients.

Supplementary Materials: The following are available online at https:/ /www.mdpi.com/article/10 $.3390 / \mathrm{jcm} 10215153 / \mathrm{s} 1$, Table S1: Spearman correlation analysis ( $r$ and $p$ values) performed between OD values obtained by ELISA test and RA features.

Author Contributions: L.A.S. supervised, designed, and conceived the study, L.A.S., M.B. and G.L.E. designed the experiment and analyzed the data statistically; S.J. drafted the manuscript and carried out the experiments; M.L.C. and G.L.E. recruited RA patients and healthy controls, analyzed the data, discussed the results, and approved the manuscript. L.A.S. revised the final version of the manuscript. All authors have read and agreed to the published version of the manuscript.

Funding: This work was supported by the he UNISS FAR fondi ricerca 2019, 2020 to L.A.S.

Institutional Review Board Statement: This study was approved by the Ethical Committee ASL 1 Sassari Prot 2149/CE/2.

Informed Consent Statement: Informed consent was obtained from all subjects involved in the study.

Data Availability Statement: The data that support the findings of this study are available from the corresponding author, upon reasonable request.

Conflicts of Interest: The authors declare no conflict of interest.

\section{References}

1. Guo, Q.; Wang, Y.; Xu, D.; Nossent, J.; Pavlos, N.J.; Xu, J. Rheumatoid arthritis: Pathological mechanisms and modern pharmacologic therapies. Bone Res. 2018, 6, 15. [CrossRef] [PubMed]

2. van Delft, M.A.M.; Huizinga, T.W.J. An overview of autoantibodies in rheumatoid arthritis. J. Autoimmun. 2020, 110, 102392. [CrossRef] [PubMed]

3. Kronzer, V.L.; Davis, J.M., 3rd. Etiologies of Rheumatoid Arthritis: Update on Mucosal, Genetic, and Cellular Pathogenesis. Curr. Rheumatol. Rep. 2021, 23, 21. [CrossRef] [PubMed]

4. Fang, Q.; Ou, J.; Nandakumar, K.S. Autoantibodies as Diagnostic Markers and Mediator of Joint Inflammation in Arthritis. Mediat. Inflamm. 2019, 2019, 6363086. [CrossRef] 
5. Holers, V.M.; Demoruelle, M.K.; Kuhn, K.A.; Buckner, J.H.; Robinson, W.H.; Okamoto, Y.; Norris, J.M.; Deane, K.D. Rheumatoid arthritis and the mucosal origins hypothesis: Protection turns to destruction. Nat. Rev. Rheumatol. 2018, 14, 542-557. [CrossRef] [PubMed]

6. Firestein, G.S.; McInnes, I.B. Immunopathogenesis of Rheumatoid Arthritis. Immunity 2017, 46, 183-196. [CrossRef] [PubMed]

7. Bo, M.; Jasemi, S.; Uras, G.; Erre, G.L.; Passiu, G.; Sechi, L.A. Role of Infections in the Pathogenesis of Rheumatoid Arthritis: Focus on Mycobacteria. Microorganisms 2020, 8, 1459. [CrossRef]

8. Bo, M.; Niegowska, M.; Eames, H.L.; Almuttaqi, H.; Arru, G.; Erre, G.L.; Passiu, G.; Khoyratty, T.E.; van Grinsven, E.; Udalova, I.A.; et al. Antibody response to homologous epitopes of Epstein-Barr virus, Mycobacterium avium subsp. paratuberculosis and IRF5 in patients with different connective tissue diseases and in mouse model of antigen-induced arthritis. J. Transl. Autoimmun. 2020, 3, 100048. [CrossRef]

9. Johansson, L.; Sherina, N.; Kharlamova, N.; Potempa, B.; Larsson, B.; Israelsson, L.; Potempa, J.; Rantapää-Dahlqvist, S.; Lundberg, K. Concentration of antibodies against Porphyromonas gingivalis is increased before the onset of symptoms of rheumatoid arthritis. Arthritis Res. Ther. 2016, 18, 201. [CrossRef]

10. Bo, M.; Erre, G.L.; Bach, H.; Slavin, Y.N.; Manchia, P.A.; Passiu, G.; Sechi, L.A. PtpA and PknG Proteins Secreted by Mycobacterium avium subsp. paratuberculosis are Recognized by Sera from Patients with Rheumatoid Arthritis: A Case-Control Study. J. Inflamm. Res. 2019, 12, 301-308. [CrossRef]

11. Yamakawa, M.; Ouhara, K.; Kajiya, M.; Munenaga, S.; Kittaka, M.; Yamasaki, S.; Takeda, K.; Takeshita, K.; Mizuno, N.; Fujita, T.; et al. Porphyromonas gingivalis infection exacerbates the onset of rheumatoid arthritis in SKG mice. Clin. Exp. Immunol. 2016, 186, 177-189. [CrossRef] [PubMed]

12. Lange, L.; Thiele, G.M.; McCracken, C.; Wang, G.; Ponder, L.A.; Angeles-Han, S.T.; Rouster-Stevens, K.A.; Hersh, A.O.; Vogler, L.B.; Bohnsack, J.F.; et al. Symptoms of periodontitis and antibody responses to Porphyromonas gingivalis in juvenile idiopathic arthritis. Pediatr. Rheumatol. Online J. 2016, 14, 8. [CrossRef] [PubMed]

13. Cheng, Z.; Meade, J.; Mankia, K.; Emery, P.; Devine, D.A. Periodontal disease and periodontal bacteria as triggers for rheumatoid arthritis. Best Pract. Res. Clin. Rheumatol. 2017, 31, 19-30. [CrossRef] [PubMed]

14. Bo, M.; Niegowska, M.; Frau, J.; Sechi, G.; Arru, G.; Cocco, E.; Sechi, L.A. IL-2 and Mycobacterial Lipoarabinomannan as Targets of Immune Responses in Multiple Sclerosis Patients. Microorganisms 2020, 8, 500. [CrossRef]

15. Perron, H.; Lang, A. The Human Endogenous Retrovirus Link between Genes and Environment in Multiple Sclerosis and in Multifactorial Diseases Associating Neuroinflammation. Clin. Rev. Allergy Immunol. 2010, 39, 51-61. [CrossRef]

16. Balada, E.; Vilardell-Tarrés, M.; Ordi-Ros, J. Implication of Human Endogenous Retroviruses in the Development of Autoimmune Diseases. Int. Rev. Immunol. 2010, 29, 351-370. [CrossRef]

17. Tugnet, N.; Rylance, P.; Roden, D.; Trela, M.; Nelson, P. Human Endogenous Retroviruses (HERVs) and Autoimmune Rheumatic Disease: Is There a Link? Open Rheumatol. J. 2013, 7, 13-21. [CrossRef]

18. Aletaha, D.; Neogi, T.; Silman, A.J.; Funovits, J.; Felson, D.T.; Bingham, C.O.; Birnbaum, N.S.; Burmester, G.R.; Bykerk, V.P.; Cohen, M.D.; et al. 2010 Rheumatoid arthritis classification criteria: An American College of Rheumatology/European League Against Rheumatism collaborative initiative. Ann. Rheum. Dis. 2010, 69, 1580. [CrossRef]

19. Aletaha, D.S. 96-Evaluation and outcomes of patients with rheumatoid arthritis. In Rheumatology, 6th ed.; Hochberg, M.C., Silman, A.J., Smolen, J.S., Weinblatt, M.E., Weisman, M.H., Eds.; Mosby: Philadelphia, PA, USA, 2015; pp. $790-801$.

20. Bo, M.; Erre, G.; Niegowska, M.; Marco, P.; Loredana, T.; Giovanna, L.; Passiu, G.; Sechi, L. Interferon regulatory factor 5 is a potential target of autoimmune response triggered by Epstein-Barr virus and Mycobacterium avium subsp. paratuberculosis in rheumatoid arthritis: Investigating a mechanism of molecular mimicry. Clin. Exp. Rheumatol. 2018, 36, 376-381.

21. Mameli, G.; Cocco, E.; Frau, J.; Marrosu, M.G.; Sechi, L.A. Epstein Barr Virus and Mycobacterium avium subsp. paratuberculosis peptides are recognized in sera and cerebrospinal fluid of MS patients. Sci. Rep. 2016, 6, 22401. [CrossRef]

22. Mameli, G.; Cossu, D.; Cocco, E.; Frau, J.; Marrosu, M.G.; Niegowska, M.; Sechi, L.A. Epitopes of HERV-Wenv induce antigenspecific humoral immunity in multiple sclerosis patients. J. Neuroimmunol. 2015, 280, 66-68. [CrossRef]

23. Tuck, M.K.; Chan, D.W.; Chia, D.; Godwin, A.K.; Grizzle, W.E.; Krueger, K.E.; Rom, W.; Sanda, M.; Sorbara, L.; Stass, S.; et al. Standard operating procedures for serum and plasma collection: Early detection research network consensus statement standard operating procedure integration working group. J. Proteome Res. 2009, 8, 113-117. [CrossRef] [PubMed]

24. Cossu, D.; Yokoyama, K.; Sechi, L.A.; Otsubo, S.; Tomizawa, Y.; Momotani, E.; Hattori, N. Humoral response against host-mimetic homologous epitopes of Mycobacterium avium subsp. paratuberculosis in Japanese multiple sclerosis patients. Sci. Rep. 2016, 6, 29227. [CrossRef]

25. Karlson, E.W.; Deane, K. Environmental and Gene-Environment Interactions and Risk of Rheumatoid Arthritis. Rheum. Dis. Clin. N. Am. 2012, 38, 405-426. [CrossRef]

26. Ercolini, A.M.; Miller, S.D. The role of infections in autoimmune disease. Clin. Exp. Immunol. 2009, 155, 1-15. [CrossRef] [PubMed]

27. Garvey, M. Mycobacterium avium subspecies paratuberculosis: A possible causative agent in human morbidity and risk to public health safety. Open Vet. J. 2018, 8, 172-181. [CrossRef] [PubMed]

28. Erre, G.L.M., G.; Cossu, D.; Muzzeddu, B.; Piras, C.; Paccagnini, D.; Passiu, G.; Sechi, L.A. Increased Epstein-Barr Virus DNA Load and Antibodies Against EBNA1 and EA in Sardinian Patients with Rheumatoid Arthritis. Viral Immunol. 2015, 28, 385-390. [CrossRef] 
29. Bo, M.; Niegowska, M.; Erre, G.L.; Piras, M.; Longu, M.G.; Manchia, P.; Manca, M.; Passiu, G.; Sechi, L.A. Rheumatoid arthritis patient antibodies highly recognize IL-2 in the immune response pathway involving IRF5 and EBV antigens. Sci. Rep. 2018, 8, 1789. [CrossRef]

30. Nelson, P.N.; Carnegie, P.R.; Martin, J.; Davari Ejtehadi, H.; Hooley, P.; Roden, D.; Rowland-Jones, S.; Warren, P.; Astley, J.; Murray, P.G. Demystified. Human endogenous retroviruses. Mol. Pathol. 2003, 56, 11-18. [CrossRef]

31. Arru, G.; Sechi, E.; Mariotto, S.; Zarbo, I.R.; Ferrari, S.; Gajofatto, A.; Monaco, S.; Deiana, G.A.; Bo, M.; Sechi, L.A.; et al. Antibody response against HERV-W in patients with MOG-IgG associated disorders, multiple sclerosis and NMOSD. J. Neuroimmunol. 2020, 338, 577110. [CrossRef]

32. Grandi, N.; Tramontano, E. HERV Envelope Proteins: Physiological Role and Pathogenic Potential in Cancer and Autoimmunity. Front. Microbiol. 2018, 9, 462. [CrossRef] [PubMed]

33. Mameli, G.; Erre, G.L.; Caggiu, E.; Mura, S.; Cossu, D.; Bo, M.; Cadoni, M.L.; Piras, A.; Mundula, N.; Colombo, E.; et al. Identification of a HERV-K env surface peptide highly recognized in Rheumatoid Arthritis (RA) patients: A cross-sectional case-control study. Clin. Exp. Immunol. 2017, 189, 127-131. [CrossRef] [PubMed]

34. Ceccarelli, F.; Saccucci, M.; Di Carlo, G.; Lucchetti, R.; Pilloni, A.; Pranno, N.; Luzzi, V.; Valesini, G.; Polimeni, A. Periodontitis and Rheumatoid Arthritis: The Same Inflammatory Mediators? Mediat. Inflamm. 2019, 2019, 6034546. [CrossRef] [PubMed]

35. Mikuls, T.R.; Thiele, G.M.; Deane, K.D.; Payne, J.B.; O’Dell, J.R.; Yu, F.; Sayles, H.; Weisman, M.H.; Gregersen, P.K.; Buckner, J.H.; et al. Porphyromonas gingivalis and disease-related autoantibodies in individuals at increased risk of rheumatoid arthritis. Arthritis Rheum. 2012, 64, 3522-3530. [CrossRef] [PubMed]

36. Rodríguez-Lozano, B.; González-Febles, J.; Garnier-Rodríguez, J.L.; Dadlani, S.; Bustabad-Reyes, S.; Sanz, M.; Sánchez-Alonso, F.; Sánchez-Piedra, C.; González-Dávila, E.; Díaz-González, F. Association between severity of periodontitis and clinical activity in rheumatoid arthritis patients: A case-control study. Arthritis Res. Ther. 2019, 21, 27. [CrossRef] [PubMed] 